\title{
Melittin induces NSCLC apoptosis via inhibition of miR-183
}

This article was published in the following Dove Press journal: OncoTargets and Therapy

\section{Dongqi Gao \\ Jingjing Zhang \\ Lu Bai \\ Fubo Li \\ Yi Dong \\ Qingshan Li}

Department of Oncology, Affiliated Hospital of Chengde Medical University, Chengde 067000, China

Correspondence: Qingshan Li Department of Oncology, Affiliated Hospital of Chengde Medical University, No 36, South Yingzi Street, Shuangqiao District, Chengde 067000, Hebei, China Email qingshan_ql@|26.com

\begin{abstract}
Background: Non-small-cell lung cancer (NSCLC) has one of the highest mortality rates among cancers worldwide, with a poor prognosis. Previous studies have reported that melittin, an active component of apitoxin, exerts anti-inflammatory and antitumor effects via vascular endothelial growth factor or FoxO1.

Methods: CCK8, flow cytometry assay and Western blotting were performed to evaluate the effect of melittin on NSCLC.

Results: The present study demonstrates that melittin activated caspase- 2 by inhibiting miR-183 expression and, thus, induced NSCLC apoptosis in both NCI-H441 cancer cell line assays and an in vivo xenograft model. The results of the cell-based assays showed that melittin $(2 \mu \mathrm{g} / \mathrm{mL})$ robustly suppressed miR-183 expression level and resulted in decreased invasion and migration abilities of NCIH441 cells. Additionally, a flow cytometry assay and Western blotting showed that melittin induced NSCLC NCI-H441 cell apoptosis along with significant elevation of caspase- 2 and Bax, which are regulators of cell apoptosis, and reduced $\mathrm{Bcl}-2$ protein expression compared with dimethyl sulfoxide control. Furthermore, subcutaneous injection of melittin $(5 \mathrm{mg} / \mathrm{kg})$ significantly suppressed NSCLC tumor growth compared with vehicle group tumors, determined through tumor size and weight.

Conclusion: Taken together, the aforementioned findings contribute to identification of a novel therapeutic target in the treatment of NSCLC, in patients diagnosed with a high expression of miR-183. Moreover, this article provides solid evidence for the inhibitory effect of melittin on NSCLC cancer cell growth.
\end{abstract}

Keywords: miR-183, melittin, NSCLC, caspase 2, apoptosis

\section{Introduction}

Lung cancer has the highest mortality rate worldwide among cancers, with the overall ratio of mortality to incidence being 0.9 . Based on the growth and metastatic ability, two types of lung cancer have been defined: small cell lung cancer and non-small-cell lung cancer (NSCLC). Moreover, among all lung cancer patients, $\sim 75 \%$ of patients are diagnosed with NSCLC. For those patients diagnosed with advanced or distant metastatic NSCLC, the survival rate is relatively low, particularly the 5-year survival rate which is $<4 \%$. ${ }^{1} \mathrm{NSCLC}$ constitutes stages I-IV, with metastases from the pathological site of diagnosis. Moreover, the 5-year survival rate for stage I and stage II NSCLC patients is 0.84 and 0.66 , respectively. ${ }^{2}$ Therefore, earlier diagnosis or detection of NSCLC results in a more positive outcome and response to therapy.

To date, a number of tests are commonly used in clinics by the physicians to diagnose lung cancer. However, the system is less than ideal. ${ }^{3,4}$ There are limitations for each diagnostic method. For example, the routine computed tomographic scan detects the smallest mass in the lungs. However, the cost is higher compared with other tests. Furthermore, patients with lung cancer have few symptom at this stage. Therefore, 
one of the toughest problems in the current clinical therapies is prognoses and diagnosis of NSCLC in preclinical routine health checkups. ${ }^{4}$ Fortunately, various novel tumor markers have been identified including exosomes, ${ }^{5}$ miRNAs, ${ }^{6,7}$ and methylated genes such as Homeobox (HOX) genes. ${ }^{8}$ These novel biomarkers are critical in further investigations regarding the biology of NSCLC and for the effective treatment of patients with metastatic NSCLC. MiRNA is a type of singlestranded RNA with 22-24 nucleotides which target mRNA by sequence-specific combination at the 3 'untranslated region of target mRNA. MiRNA contributes to a series of biological processes such as proliferation, migration, invasion, apoptosis, and carcinogenesis. Furthermore, miRNA is present in serum, saliva, and urine, making it clinically available as an easily identified tumor marker. Therefore, miRNA may contribute to development of novel strategies for cancer diagnosis and therapy. ${ }^{9}$

miR-183 is a member of miR-183-96-182 cluster which is composed of miR-183, miR-96, and miR-182. This is a well-conserved miRNA cluster with a homologous sequence. Therefore, even small differences in the sequence among miR-183 family members may result in large distinctions in their targeting mRNAs. ${ }^{10}$ Currently, compelling evidence has revealed several potential pathways to be regulated by the expression of the miR-183 family. For one part, the published discovery by Tang et al revealed that the $\beta$-catenin/ TCF/LEF-1 complex may bind to the miR-183-96-182 cluster, and further demonstrated that the binding site is located at the promoter region of the miR-183 sequence. ${ }^{11}$ Moreover, it is well known that the Smad2/Smad4 complex, which is critically important for cell growth and development, directly binds to TCF- $\beta$ in the $\beta$-catenin/TCF/LEF- 1 complex. Therefore, miR-183 indirectly regulates several transcription factors such as $\beta$-catenin/TCF/LEF-1 which have an essential role in carcinogenesis. ${ }^{12,13}$ Previous studies involving MYCN and other tumor-associated genes have demonstrated that these genes bind the miR-183-96-182 cluster and are involved in the development of nervous and immune systems. ${ }^{14,15}$ Additionally, the oncogenic role of miR-183-96-182 cluster is well documented in various types of cancers, such as gastric cancer, bladder cancer, lung cancer, cancer of the retina and so on. ${ }^{11-18}$ Overall, the role of the miR-183 family is well established in NSCLC development. Therefore, targeting of the miR-183 cluster may be a promising therapeutic strategy.

Melittin is a critical active component that is extracted from honeybee venom. ${ }^{19}$ To date, several advances have been made in the development of its antimicrobial, antiinflammation, and antitumor activities. ${ }^{20-23}$ Socarras et al reported the antimicrobial activity of melittin..$^{21}$ In addition, Lee et al published the in vivo antitumor effect of melittin in lung carcinoma and demonstrated that the antitumor effect occurs via regulation of tumor-associated macrophages. ${ }^{22}$ Furthermore, Zhang and Chen confirmed the antitumor effect of melittin occurs via inhibition of the vascular endothelial growth factor signaling pathway and hypoxia-inducible factor expression in NSCLC cells. ${ }^{23}$ Additionally, other signaling pathways have been reported to be involved in the antitumor activity of melittin, including MMP-9 or PI3K/ $\mathrm{Akt} / \mathrm{mTOR}$ in breast carcinoma cell invasion and motility, PTEN in hepatocellular carcinoma, and MMP-2 in glioblastoma cell apoptosis. ${ }^{20,24}$ The majority of published studies involving melittin focus on antitumor mechanisms from the component of signaling pathway. However, investigations regarding the association between miRNA and the melittin are limited. The present study investigated the effect and underlying mechanism of melittin on miR-183 expression in NSCLC. It was demonstrated that miR-183 was downregulated by melittin and thus activated caspase-2 (CASP2) to induce NCSLC apoptosis. Taken together, these findings may highlight a new direction for further clinical NSCLC therapy, particularly for patients with high miR-183 expression levels.

\section{Materials and methods \\ Cell culture}

Human lung NSCLC NCI-H441 and A549 cell lines were purchased from Type Culture Collection of the Chinese Academy of Sciences (Shanghai, China). Human lung BEAS-2B epithelial cells were provided by American Type Culture Collection (ATCC, Rockville, MD, USA). The cells were cultured in RPMI 1640 medium (Sigma-Aldrich, St Louis, MO, USA) supplemented with 10\% fetal bovine serum (Thermo Fisher Scientific, Waltham, MA, USA) and ampicillin $(20 \mu \mathrm{g} / \mathrm{mL}$, Sigma-Aldrich). Cells were incubated at $37^{\circ} \mathrm{C}$ with $5 \% \mathrm{CO}_{2}$ in a humidified cell culture incubator (Sanyo, Tokyo, Japan). For all experiments, biological groups were designed according to the concentrations of melittin $(0,0.5,1,2,4 \mu \mathrm{g} / \mathrm{mL})$.

\section{MTT assay}

The reduction of MTT by metabolically active cells was used to measure cell growth. MTT-based kit (cat\# TOX1) was purchased from Sigma-Aldrich and used to detect cell proliferation ability according to the manufacturer's protocol. Briefly, $1 \times 10^{3} \mathrm{NCI}-\mathrm{H} 441$, A549, or BEAS-2B cells at the logarithmic growth phase were implanted into each well in the 96-well plate (Corning Incorporated, New York, NY, USA). Then, $200 \mu \mathrm{L}$ melittin with dose titration $(0,0.5,1,2,4 \mu \mathrm{g} / \mathrm{mL})$ 
was added into each well of the plate when the cells were totally adherent with triplicate biological repeats. Cells were cultured at $37^{\circ} \mathrm{C}$ with $5 \% \mathrm{CO}_{2}$ in the cell culture incubator for 24, 48, and 72 hours. For the detection of the effect of miR-183 mimics (Shanghai GenePharma Co., Ltd, Shanghai, China) on the proliferation of NCI-H441, NCI-H441 cells were firstly transfected with miR-183 mimics or scramble control vector (Shanghai GenePharma Co., Ltd) using the transient transfection reagent Lipofectamine ${ }^{\circledR} 2000$ for 6 hours (Thermo Fisher Scientific) according to the manufacturer's instructions, and then replaced with $2 \mu \mathrm{g} / \mathrm{mL}$ melittin $(200 \mu \mathrm{L} /$ well $)$ for a further 72 hours culture at $37^{\circ} \mathrm{C}$. Twenty microliters of MTT $(5 \mathrm{mg} / \mathrm{mL})$ solutions were added to each well at the end of culture. Subsequently, the cells were further incubated for 4 hours. At the end of incubation, the supernatants were carefully removed with a pipette. Prior to reading of absorbance value under the microplate reader (cat\# 168-1130; Bio-Rad Laboratories, Hercules, CA, USA), $150 \mu \mathrm{L}$ dimethyl sulfoxide (DMSO; Sigma-Aldrich Co., St Louis, MO, USA) was added into each well. The cell proliferation rate was calculated from the absorbance value (OD) at a wavelength of $450 \mathrm{~nm}$.

\section{Transwell invasion assay}

For in vitro cell migration and invasion assays, the protocol published online by Justus et al was followed. ${ }^{25}$ Briefly, $100 \mu \mathrm{L} \mathrm{NCI-H441} \mathrm{cells}\left(3 \times 10^{6}\right.$ cells/well $)$ treated with melittin or vehicle were plated on the top of the membrane in a Transwell insert into the 24-well plate (Corning Incorporated). When the cells settled down, $600 \mu \mathrm{L}$ of $30 \%$ fetal bovine serum in RPMI 1640 medium was added into the bottom of the lower chamber. Twenty-four hours later, the remaining culture medium and the cells that did not migrate from the top of the membrane were removed carefully and the migrated cells were fixed and stained with crystal violet (Thermo Fisher Scientific) at room temperature for 48 hours. The cells in different fields of view were counted under light microscope, $200 \times$ (Leica, Buffalo Grove, IL, USA). The cell migration and invasion rates were analyzed with the average sum of the counted cell numbers.

\section{Wound healing migration assay}

NCI-H441 cells at the logarithmic growth phase $\left(6 \times 10^{4}\right)$ were seeded into each well in the six-well plates (Corning Incorporated) and cultured at $37^{\circ} \mathrm{C}$ with $5 \% \mathrm{CO}_{2}$ for 24 hours. At that time, the wells were mostly confluent with the growing cells. A vertical wound was created through the cell monolayer using $1,000 \mu \mathrm{L}$ pipette tip by pressing firmly and swiftly against the top of the tissue culture plate. Then, the media and cell debris were carefully removed by aspiration, and $2 \mu \mathrm{g} / \mathrm{mL}$ melittin or DMSO ( $2 \mathrm{~mL} /$ well) was added for further 24 hours culture at $37^{\circ} \mathrm{C}$ with $5 \% \mathrm{CO}_{2}$. Wound images were captured under a light microscope, $10 \times$ (Leica) at the end of the culture period. The snapshot picture was used to analyze the distance between the two border sides of the wound using a scale bar, and the migration index was calculated by normalizing to DMSO group.

\section{Flow cytometry analysis and terminal deoxynucleotidyl transferase dUTP nick end labeling (TUNEL) of apoptotic cells}

In vitro cellular apoptosis was evaluated using an Annexin V-fluorescein isothiocyanate and propidium iodide (PI)staining kit (Thermo Fisher Scientific) following the manufacturer's instructions. Briefly, $2 \times 10^{6} \mathrm{NCI}-\mathrm{H} 441$ cells were implanted in $100 \mathrm{~mm}$ dishes (Corning Incorporated) and then treated with melittin $(1,2 \mu \mathrm{g} / \mathrm{mL})$ or DMSO. Following 72 hours incubation at $37^{\circ} \mathrm{C}$ with $5 \% \mathrm{CO}_{2}$, the cells were lysed with trypsin at $37^{\circ} \mathrm{C}$ with $5 \% \mathrm{CO}_{2}$ for 5 minutes and collected following washing twice with cold PBS (Thermo Fisher Scientific). Then, $500 \mu \mathrm{L}$ binding buffer (Thermo Fisher Scientific) was used to resuspend the cells. Following this, the cells were stained with Annexin V-fluorescein isothiocyanate and PI and further incubated for 5 minutes at room temperature before running flow cytometry (BD Biosciences). For each group, the samples were run in triplicate.

Cell apoptosis ability of the tumor tissues was measured in vivo with a TUNEL staining assay. Briefly, the tumor tissues were dissected and fixed at room temperature with 4\% paraformaldehyde in PBS for 1 hour in a slow rotary motion. The TUNEL assays were performed by using the Click-It ${ }^{\mathrm{TM}}$ TUNEL Colorimetric IHC Detection kit (Thermo Fisher Scientific) according to the manufacturer's protocol. 4',6-Diamidino-2-phenylindole and TUNEL double staining were used to count the total cell number in the given observed areas. The apoptotic cells were determined as the number of double-positive cells.

\section{Predicted target analysis of miR-I83 and luciferase assay}

An online database MiRecords (http://c1.accurascience.com/ $\underline{\text { miRecords } /)^{35}}$ was used to predict the potential binding site of CASP2 on miR-183. This online database comprises two parts: one for validated targets and the other for predicated targets. The predicated target sector integrates the results of several online miRNA target predication tools such as DIANA-microT, MicroInspector, and miTarget. Researchers are able to predict the binding site of the miRNA of interest to its targets using this database. The wild-type CASP2 and the 
mutant CASP2 were synthesized and validated by sequencing (GenePharma, Shanghai, China). The psiCHECK2 vector was used to construct the psiCHECK2-Wt and psiCHECK2Mut, which were transfected into NCI-H441 cells with NC control or miR-183 mimics for 24 hours. A Dual-Luciferase Reporter Assay (Promega) was used to detect the luciferase activity according to the manufacturer's protocol.

\section{$\mathrm{NCl}-\mathrm{H} 44 \mathrm{I}$ subcutaneous in vivo xenograft tumor model}

The animal experimental protocol was approved by the Institutional Animal Care and Use Committee at the affiliated hospital of Chengdu University. All experiments were conducted in accordance with the guidelines for animal care and welfare of China. Briefly, NCI-H441 cells transfected with miR-183 mimics or mock vectors $\left(8 \times 10^{7}\right.$ cells in $100 \mu \mathrm{L}$ PBS) were mixed 1:1 with Matrigel and subcutaneously injected into the right flank of each 6-8-week-old balb/c nu/nu mouse (Vital River, Beijing, China). Then, $5 \mathrm{mg} / \mathrm{kg}$ melittin or vehicle was orally administered to the respective groups daily for 4 weeks. The tumor size was monitored weekly using calipers, and the body weight of the mice was also monitored once per week. Tumor volumes (TV) were calculated using the following formula: TV=(length $\times$ width $\left.^{2}\right) / 2$. Both length and width were measured in $\mathrm{mm}$. Mice were euthanized at the termination of the experiment and tumors from each group were excised for weighing on electronic scales. Then, a portion of each tumor was fast frozen in liquid nitrogen for further measurements, while the remaining tumor sections were lysed for protein analysis.

\section{Real-time polymerase chain reaction (PCR) analysis}

NCI-H441 cells were incubated with melittin $(0.5,1,2$, $4 \mu \mathrm{g} / \mathrm{mL}$ ) or DMSO at $37^{\circ} \mathrm{C}$ with $5 \% \mathrm{CO}_{2}$ and harvested following a 72-hour culture period. Total RNA was extracted from these cells using PicoPure ${ }^{\mathrm{TM}}$ RNA Isolation Kit (Arcturus, Sunnyvale, CA, USA) following the manufacturer's protocol. Then, $2 \mu \mathrm{g}$ of RNA was utilized for cDNA synthesis using SuperScript ${ }^{\mathrm{TM}}$ III first-strand synthesis system kit (Thermo Fisher Scientific). The reverse transcription reaction was completed at $55^{\circ} \mathrm{C}$ in 30 minutes. Following the reverse transcription reactions, quantitative PCR (qPCR) was performed with TaqMan ${ }^{\mathrm{TM}}$ gene expression master mix (cat\# A25576, Thermo Fisher Scientific). TaqMan ${ }^{\mathrm{TM}}$ Advanced miRNA Assay (cat\# 4364338, Thermo Fisher Scientific) was used to detect miRNA levels, and reference gene U6 (cat\# 4427975, Thermo Fisher Scientific) was used as an internal control. The qPCR procedure includes two stages: hold stage and PCR stage. For hold stage: step 1: heating from $25^{\circ} \mathrm{C}$ to $95^{\circ} \mathrm{C}$ at a rate of $1.6^{\circ} \mathrm{C} / \mathrm{s}$, holding for 2 minutes at $50^{\circ} \mathrm{C}$ and step 2: heating from $50^{\circ} \mathrm{C}$ to $95^{\circ} \mathrm{C}$ at a rate of $1.6^{\circ} \mathrm{C} / \mathrm{s}$, holding for 10 minutes at $95^{\circ} \mathrm{C}$. For qPCR stage: step 1: initial denaturation at $95^{\circ} \mathrm{C}$ for 15 seconds and step 2: annealing extension at $60^{\circ} \mathrm{C}$ for 1 minute. The temperature was reduced from $95^{\circ} \mathrm{C}$ to $60^{\circ} \mathrm{C}$ at the rate of $1.6^{\circ} \mathrm{C} / \mathrm{s}$; the denaturation and extension stages were repeated for 40 cycles using ViiA ${ }^{\text {TM }}$ seven system (Bio-Rad Laboratories). Based on the real-time PCR results of $\mathrm{Ct}$ number, the RNA expression was calculated using the $2^{-\Delta \Delta C t}$ method $^{26}$ and normalized to the U6 gene, which was defined as an internal reference control gene for miRNA.

\section{Western blotting}

For Bax and Bcl-2 protein expression detection, NCI-H441 cells were treated with DMSO, melittin $(2 \mu \mathrm{g} / \mathrm{mL})$, or melittin combo with miR- 183 mimics at $37^{\circ} \mathrm{C}$ with $5 \% \mathrm{CO}_{2}$ for 72 hours. CASP 2 protein expression was detected from the treated NCI-H441 cells and the treated tumors. Briefly, RIPA buffer (Sigma-Aldrich) was used to lyse the cells or tumor tissue. A BCA Protein Assay Kit (Thermo Fisher Scientific) was used to quantify the protein concentration. Approximately $30 \mu \mathrm{g}$ of the extracted total protein from each group was loaded per lane and resolved by electrophoresis with $10 \%$ Tris-sodium dodecyl sulfate gel. Following electrophoresis, the proteins were semidry transferred to polyvinylidene fluoride membranes (Thermo Fisher Scientific). For subsequent blocking and antibody incubation, an iBind ${ }^{\mathrm{TM}}$ kit (Thermo Fisher Scientific) was used according to the manufacturer's protocol. Briefly, the prepared diluted primary antibodies, iBind $^{\mathrm{TM}}$ Flex/iBind ${ }^{\mathrm{TM}}$ Flex FD solution, and the prepared diluted secondary antibodies, iBind Flex/iBind Flex FD solution, were sequentially added to each lane. Membrane was incubated overnight at room temperature and rinsed in water before immune detection. The following primary antibodies were purchased from Thermo Fisher Scientific: anti-Bax (cat\# 33-6400; 1:100), anti-CASP2 (cat\# PA5-60493; 1:200), anti-Bcl-2 (cat\# MA5-11757; 1:300), and anti-GAPDH (cat\# MA5-15738; 1:1,000). The secondary antibodies (HRP-antirabbit, IgG cat\# 31460; HRP-anti-goat IgG, cat\# A27011; Thermo Fisher Scientific) were used at 1:3,000. The signals were detected with SuperSignal West Femto Maximum Sensitivity Substrate (Thermo Fisher Scientific), followed by specific protein detection with Bio-Rad ChemiDoc image (Bio-Rad Laboratories). 


\section{Statistical analysis}

Statistical analysis was conducted to determine the differences between two groups using a two-tailed Student's $t$-test available in GraphPad Prism 7 (GraphPad Software, Inc., La Jolla, CA, USA). A $P$-value $<0.01$ was considered to indicate a statistically significant difference, whereas a $P$-value $<0.05$ was considered to indicate a difference that was not significant $(P<0.05, P<0.01)$. All experiments were performed in triplicate and all values were presented as the mean \pm SD.

\section{Results}

\section{Melittin inhibits $\mathrm{NCl}-\mathrm{H} 44$ I cell growth via inducing apoptosis}

To assess the effect of melittin on NCI-H441 cell growth, we analyzed the cell viability by MTT assay. The cells were treated with several doses of melittin $(0,0.5,1,2$, or $4 \mu \mathrm{g} / \mathrm{mL}$ ) for 24, 48, and 72 hours. As shown in Figure 1A, melittin inhibited cell proliferation of NCI-H441 in a dosedependent manner. In particular, 72 hours of treatment with melittin significantly decreased NCI-H441 cell growth at the concentration of 2 or $4 \mu \mathrm{g} / \mathrm{mL}(P<0.01)$. To determine whether the lung cancer cell growth inhibitory effect of melittin was due to the induction of apoptotic cell death, we evaluated cell apoptosis by Annexin V/PI staining assay. NCI-H441 cells were treated with melittin $(0,1$, or $2 \mu \mathrm{g} / \mathrm{mL})$. The cell apoptosis rate was increased by melittin in a concentration-dependent manner. Treatment with $2 \mu \mathrm{g} / \mathrm{mL}$ melittin significantly induced NCI-H441 cell apoptosis $(P<0.01$; Figure 1B and C). Similarly, melittin dose dependently inhibited A549 cell growth due to the increased apoptosis and had very limited toxicity on normal lung epithelial cells (Figure S1A-D). Thus, melittin inhibited NSCLC cell growth by inducing apoptosis.

\section{Melittin inhibits NSCLC migration and invasion}

To further demonstrate the effect of melittin on NSCLC, we assayed the migration and invasion ability of NCI-H441
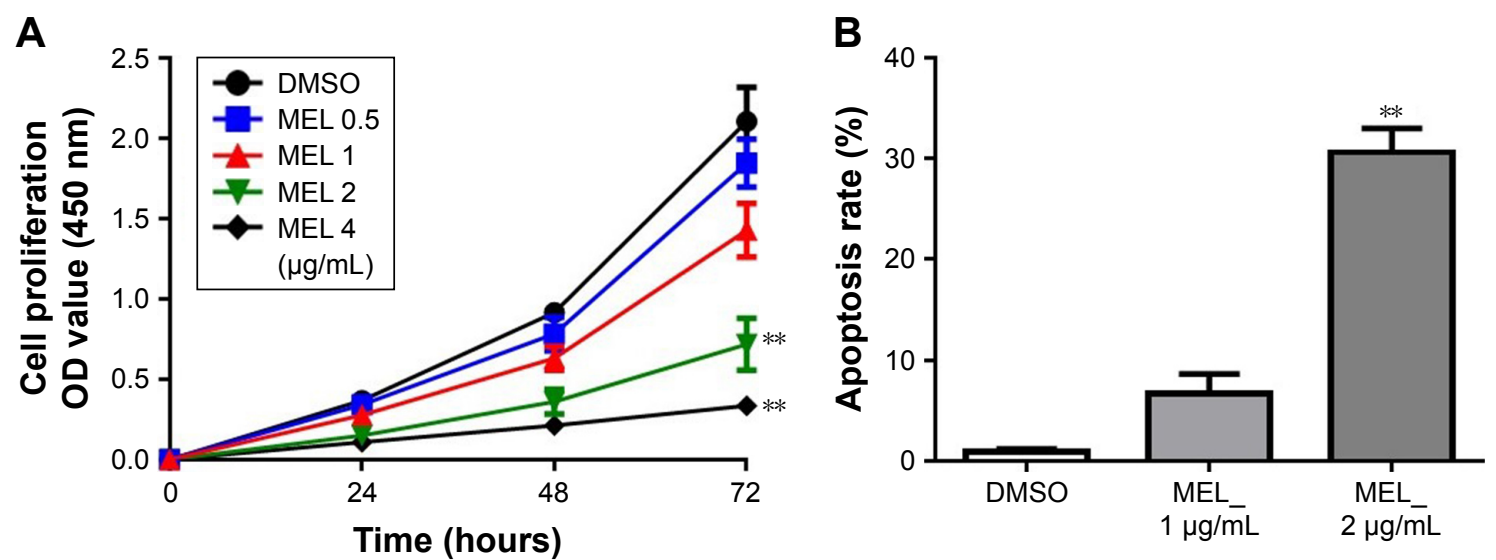

C

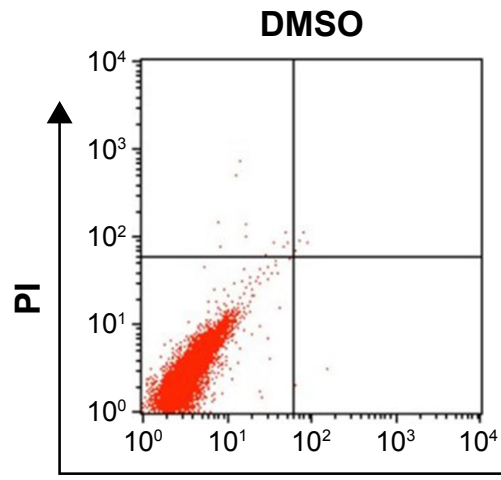

MEL_1 $\mu \mathrm{g} / \mathrm{mL}$

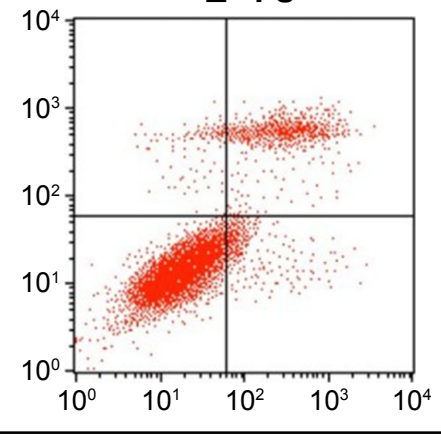

MEL_2 $\mu \mathrm{g} / \mathrm{mL}$

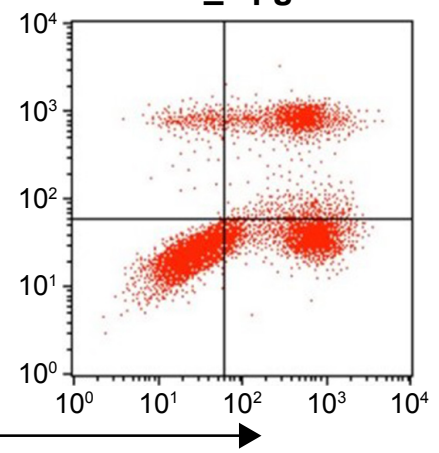

Annexin V

Figure I Effects of MEL on lung cancer cell proliferation and apoptosis.

Notes: Human lung cancer cell line $\mathrm{NCl}-\mathrm{H} 44 \mathrm{I}$ was used to validate the cell viability and cell apoptosis. (A) $\mathrm{NCl}-\mathrm{H} 44 \mathrm{I}$ cell proliferation rate was detected with MTT assay when treated with MEL $(0,0.5, \mathrm{I}, 2$, or $4 \mu \mathrm{g} / \mathrm{mL})$ for 24,48 , and 72 hours $(P<0.0 \mathrm{I})$. (B, C) Annexin V/PI was used to validate the cell apoptotic rate of NCl-H44I cells exposed to MEL (I or $2 \mu \mathrm{g} / \mathrm{mL})$ for 72 hours $(P<0.01)$. ${ }^{* *} P<0.0$ I compared with control group.

Abbreviations: DMSO, dimethyl sulfoxide; MEL, melittin; PI, propidium iodide. 
A
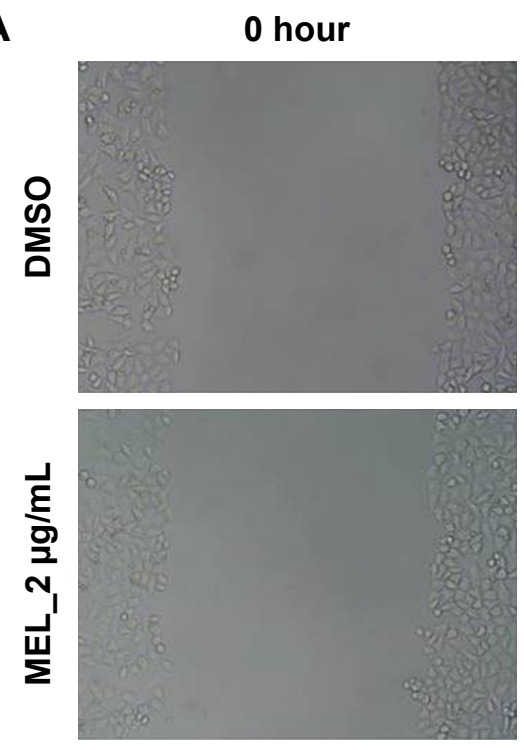

C

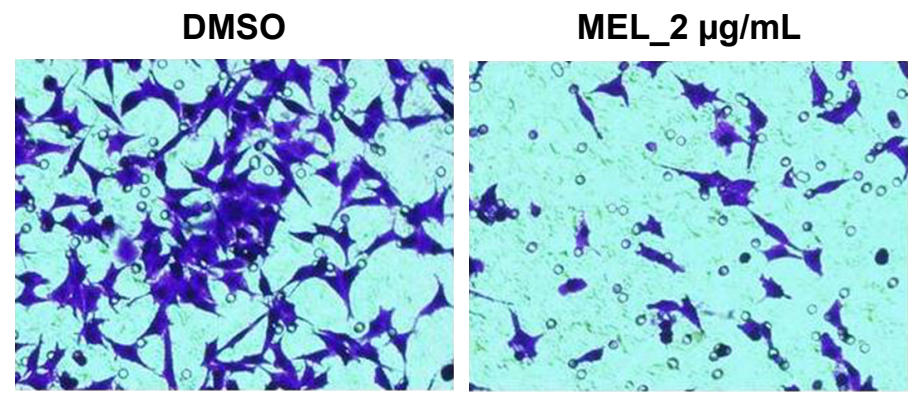

24 hours
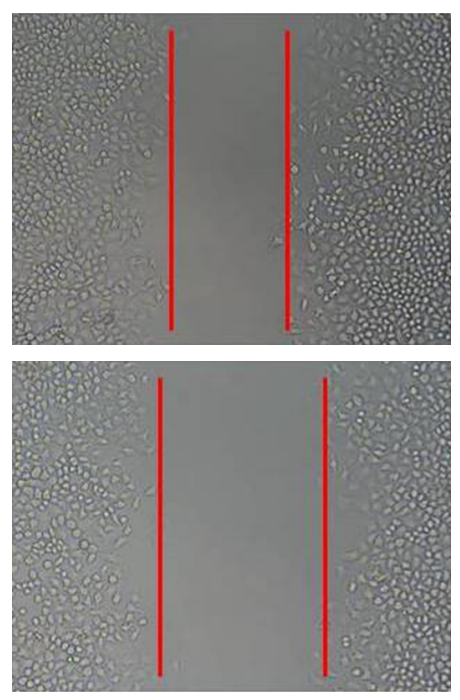

MEL_2 $\mu \mathrm{g} / \mathrm{mL}$
B

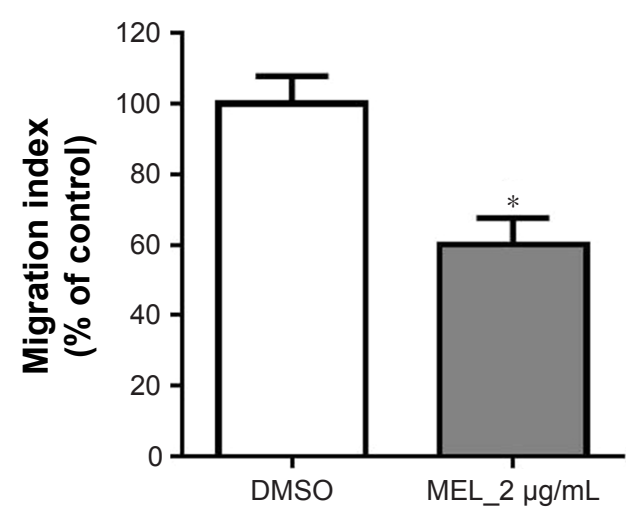

D

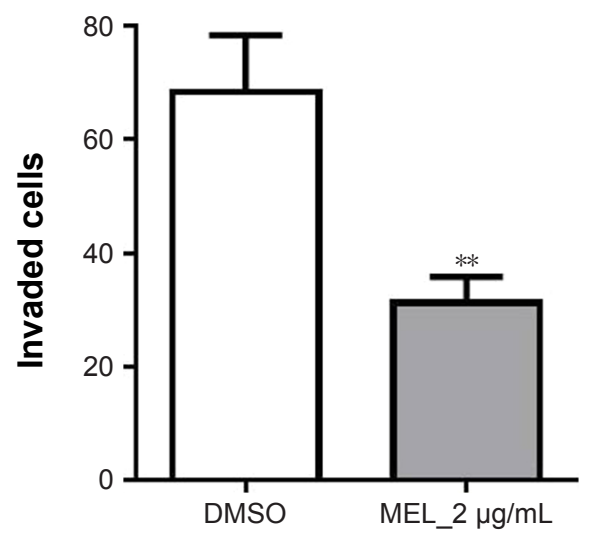

Figure $2 \mathrm{MEL}$ inhibits lung cancer cell migration and invasion.

Notes: (A) NCl-H44 I with MEL $(0$ or $2 \mu \mathrm{g} / \mathrm{mL})$ at 24 hours in wound-healing assay $(\mathrm{I} 0 \times)$. (B) Migration index $(P<0.05)$. (C) Invaded NCl-H44I cells (with crystal violet) in Transwell assay $(20 \times)$. (D) Quantification of invaded cells $(P<0.0 \mathrm{I})$. $* P<0.05$, $* * P<0.0$ I compared with control group. Abbreviations: DMSO, dimethyl sulfoxide; MEL, melittin.

cells treated with DMSO or $2 \mu \mathrm{g} / \mathrm{mL}$ melittin for 24 hours. As shown in Figure 2A, we found the wound was wider with melittin treatment compared with DMSO. The migration index, which is the quantification of the distance between the two borders of the wound $(P<0.05$; Figure $2 \mathrm{~B})$. Furthermore, less invaded cells, which were stained by crystal violet, were detected in the melittin group compared with the DMSO group $(P<0.01$; Figure $2 \mathrm{C}$ and $\mathrm{D})$. Moreover, based on the morphological observations, NCI-H441 cells treated with $2 \mu \mathrm{g} / \mathrm{mL}$ melittin exhibited a smaller size with a round single-cell shape compared with DMSO controltreated cells (Figure 2C).

\section{Melittin inhibits miR-I83 expression}

It is well known that miR-183 is highly expressed in NSCLC and has been identified as a potential biomarker for lung cancer. ${ }^{17,18}$ We first validated the effect of melittin on miR-183 expression in NCI-H441 cells. As indicated in the "Results" section, melittin dose dependently inhibited
miR-183 expression in 72 hours (Figure 3A). In addition, $2 \mu \mathrm{g} / \mathrm{mL}$ melittin downregulated miR-183 level at an early time point and had no effect on miR-126 and miR-210, which are also reported to be involved in NSCLC tumorigenesis ${ }^{17}$ (Figure S2A-C). To further demonstrate the effect of melittin on miR-183, we detected cell proliferation with melittin or melittin combination with miR-183 mimics. As shown in Figure 3B, miR-183 mimics robustly increased the proliferation rate of NCI-H441 cells by interfering with the inhibitory effect of melittin on cell proliferation $(P<0.05)$. Previous investigations have demonstrated that CASP2 is a potential target of miR-183-5 p. ${ }^{16}$ We predicted the binding site of miR-183 and CASP2 via the online database which was introduced in the "Materials and methods" section. As shown in Figure 3C, the binding site of miR-183 was on CASP2 3'untranslated region with the sequence GUGCCA. Furthermore, the result of Dual-Luciferase Reporter Assay confirmed CASP2 as the target of miR-183-5 p (Figure 3D). 
A

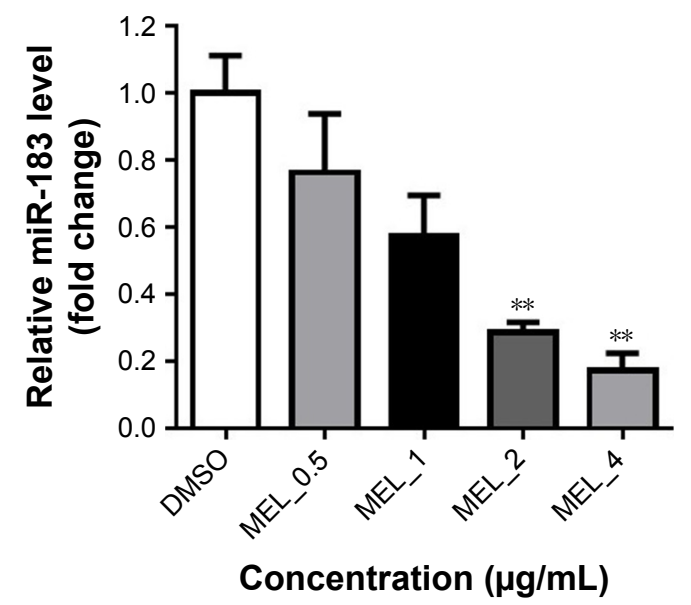

B
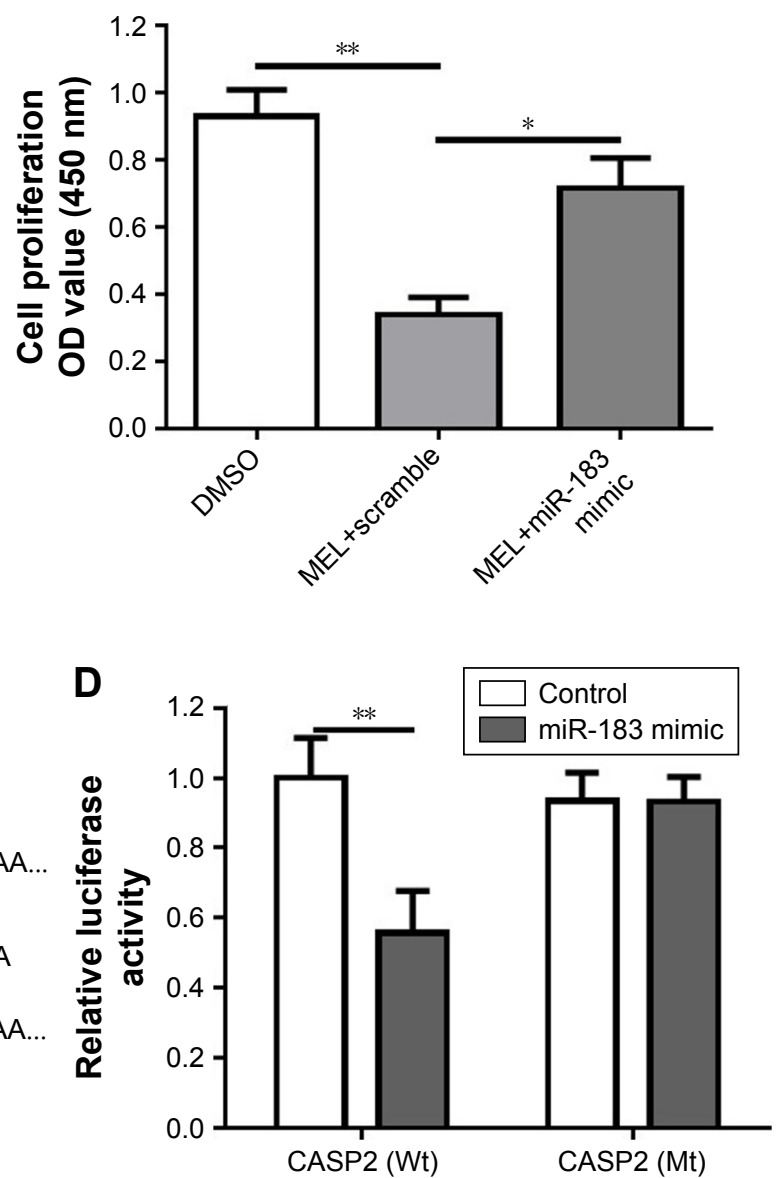

C Position of 2,595-2,601
of CASP2 3' UTR

hsa-miR-183-5p

Mutant of CASP2 3' UTR
Predicted pairing of target region 5'...UGUAUUGCCAUCGGGUGCCAAA. 3' GuCACUUAAGAUGguCACGguA

5'...UGUAUUGCCAUCGGGCUACCAA...

Figure 3 MEL downregulates miR-183 mRNA expression by targeting CASP2.

Notes: (A) miR-I83 mRNA expression level was detected with RT-qPCR on NCl-H44I cells treated with MEL $(0,0.5,1,2$, or $4 \mu g / \mathrm{mL})$ for 72 hours. (B) NCl-H44I cell proliferation rate after 72 hours co-culture with DMSO, MEL $(2 \mu \mathrm{g} / \mathrm{mL})$, and MEL combined with miR-I 83 mimics $(P<0.05, P<0.01)$. (C) Gene structure of caspase-2 showing the predicted pairing position in its 3' UTR with the sequence of GUGCCA to target miR-I83. (D) The psiCHECK2-CASP2 Wt or psiCHECK2-CASP2 Mut was transfected into $\mathrm{NCl}-\mathrm{H} 44 \mathrm{I}$ cells with $\mathrm{NC}$ control or miR- 183 mimics for 24 hours. $* P<0.05$, $* * P<0.01$ compared with control group.

Abbreviations: CASP2, caspase 2; DMSO, dimethyl sulfoxide; MEL, melittin; RT-qPCR, reverse transcriptase quantitative polymerase chain reaction; UTR, untranslated region.

\section{The effect of melittin on expression levels of apoptotic proteins}

To figure out the mechanism of melittin on inducing NSCLC cell apoptosis, the expression levels of Bax, Bcl-2, and CASP2 (apoptotic cell death-related proteins) was evaluated by Western blotting. The expression levels of apoptotic proteins (Bax, CASP2) were significantly increased $(P<0.01$; Figure $4 \mathrm{~A}-\mathrm{C})$, but that of Bcl-2 was decreased $(P<0.05$; Figure $4 \mathrm{~A}$ and $\mathrm{D})$ on treatment of $2 \mu \mathrm{g} / \mathrm{mL}$ melittin compared with DMSO treatment. To further demonstrate that melittin via miR-183 induced NCI-H441, the miR-183 mimic was transfected into cells along with administration of melittin. The results shown in Figure 4 indicate that miR-183 mimics blocked the induction of apoptotic regulatory proteins by melittin. Thus, the inhibitory effect of melittin on NCI-H441 was by downregulation of miR-183, which resulted in induction of CASP2 and Bax activation.

\section{Melittin inhibits tumor growth in $\mathrm{NCl}-\mathrm{H} 44 \mathrm{I}$ xenograft model}

In order to determine whether melittin inhibited NSCLC growth activity in vivo, two modified NCI-H441 cell lines were established. One cell line was transfected with miR-183 mimics and the other was only transfected with scramble vector. Mice were implanted with these two modified NCI-H441 cells, respectively, for the vehicle group, melittin group, or melittin combined with miR-183 mimics group. Results showed that melittin significantly inhibited tumor growth compared with control group in the 4-week time point. The tumor size was $450 \mathrm{~mm}^{3}$ compared with the control group, where it was $1,500 \mathrm{~mm}^{3}$. Moreover, in melittin with 
A

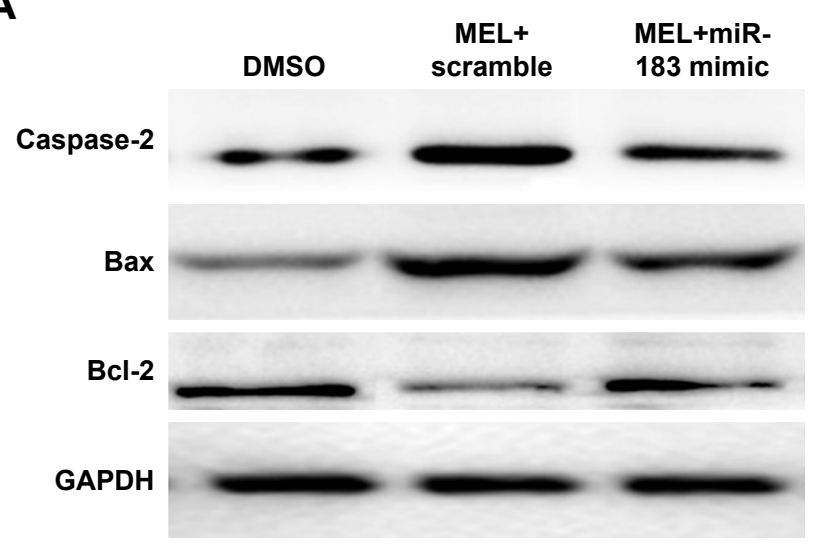

C

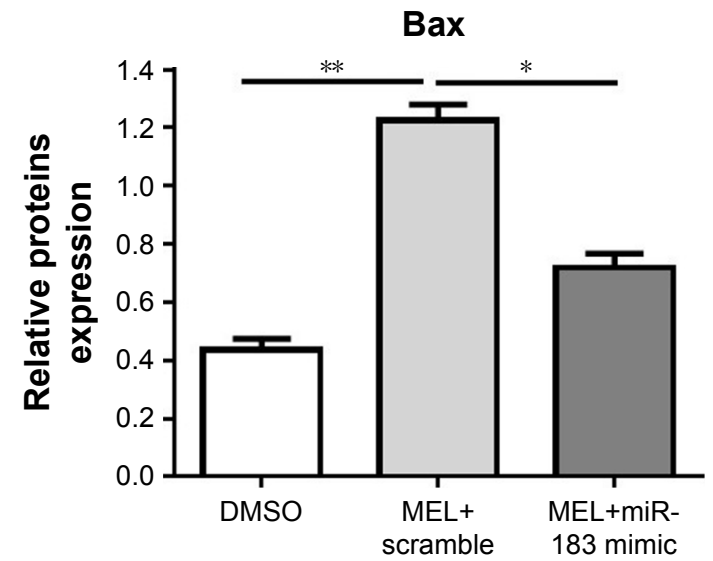

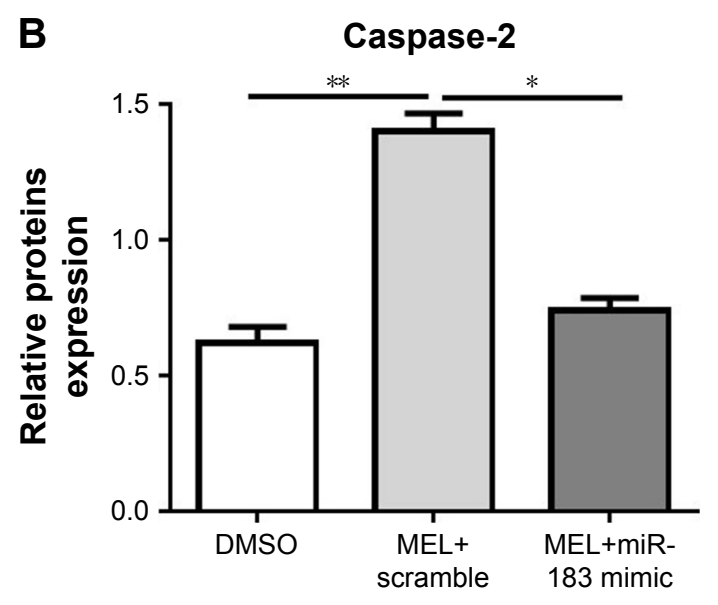

D

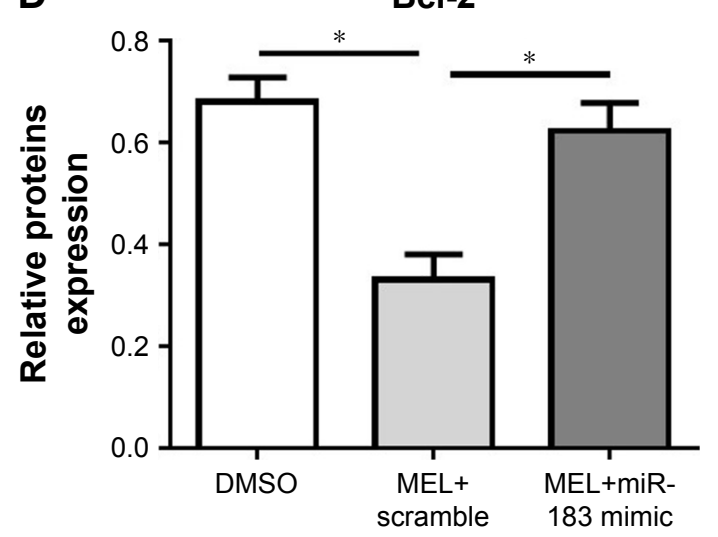

Figure 4 Effect of MEL on apoptosis-related proteins.

Notes: (A) Caspase-2, Bax, and Bcl-2 protein expression levels in NCl-H44I cells treated with DMSO, MEL (2 $\mu \mathrm{g} / \mathrm{mL})$, and MEL combined with miR-I83 mimics for 72 hours. Quantification of protein expression levels by normalizing to GAPDH (B) caspase-2, (C) $B a x$, and (D) $B c l-2(P<0.05, P<0.01)$. ${ }^{P}<0.05$, $* * P<0.01$ compared with control group.

Abbreviations: DMSO, dimethyl sulfoxide; MEL, melittin.

miR-183 mimics group, the tumor size was $\sim 1,000 \mathrm{~mm}^{3}$. The tumor growth was significantly enhanced by miR-183 mimics compared with melittin (Figure 5A). At the end of the experiment, the tumor size in the melittin group was the smallest when compared to the vehicle and melittin with miR-183 mimics groups (Figure 5B). Moreover, the tumor weight in the melittin group (0.5 g) was much smaller compared with those in the control group $(1.6 \mathrm{~g})$ or the melittin plus miR-183 mimics (1.5 g) group (Figure 5C). No obvious body weight changes were observed among these three groups (Figure 5D).

\section{Melittin induces apoptosis and enhances CASP2 expression in $\mathrm{NCl}-\mathrm{H} 44 \mathrm{I}$ tumors}

To validate the inhibitory activity of melittin on NCI-H441 tumors, we firstly determined the apoptosis rate using a TUNEL assay. The results in Figure 6A and $\mathrm{B}$ indicate that more TUNEL-positive cells were seen in melittin group than in DMSO control group. Melittin significantly induced
NCI-H441 tumor apoptosis in vivo. Furthermore, the CASP protein expression detected with Western blotting further confirmed that melittin induced NCI-H441 tumor apoptosis. CASP2 was significantly upregulated by melittin compared with that in vehicle-treated tumors (Figure 6C and D), which was consistent with the findings in the in vitro cell line assays (Figure 4A and B).

\section{Discussion}

In recent studies, researchers have aimed to clarify the mechanisms of melittin that result in an inhibitory effect on NSCLC growth. It has been previously reported that melittin significantly inhibits the vascular endothelial growth factor signaling pathway in NSCLC cell lines and xenograft lung carcinoma tumor mouse model..$^{22,23}$ The present study investigated the potential effects and the underlying mechanisms of melittin in NCI-H441 cells both in vitro and in an in vivo xenograft model. It was demonstrated that melittin inhibited NCI-H441 cell and tumor growth. Additionally, in vitro 
A

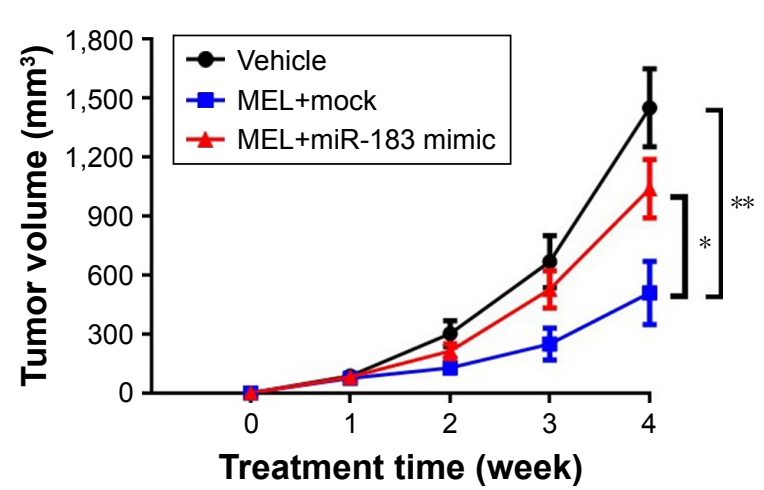

C

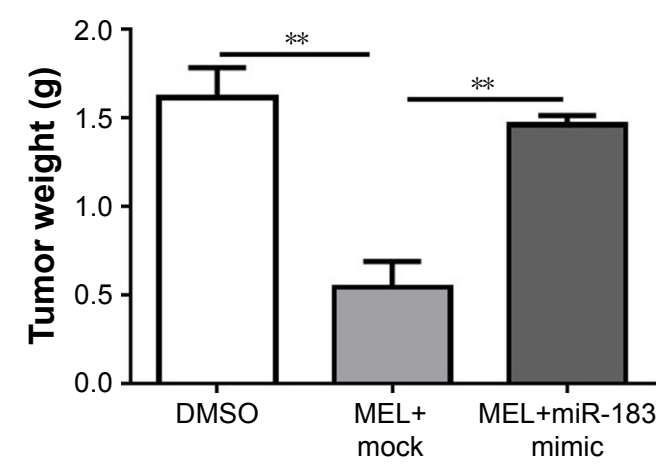

B

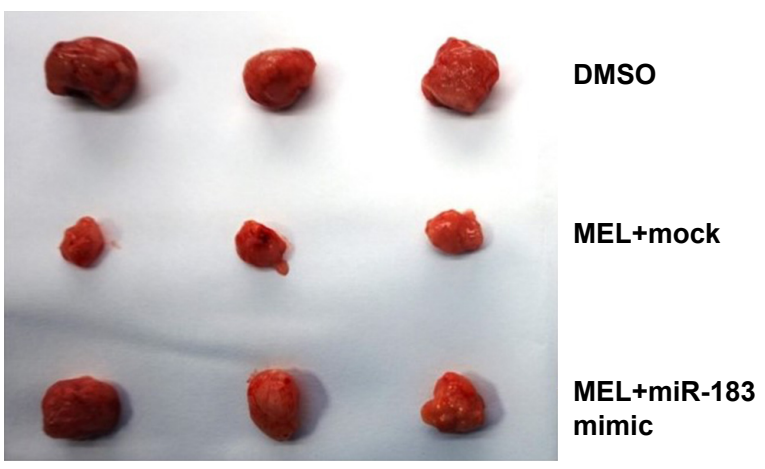

D

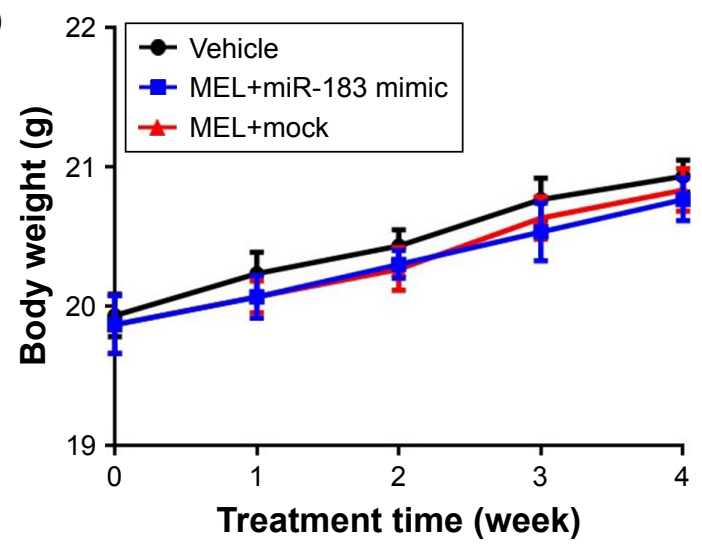

Figure 5 MEL inhibits tumor growth in $\mathrm{NCl}-\mathrm{H} 44 \mathrm{I}$ xenograft model.

Notes: (A) Tumor volume from 0 to 4 weeks of treatment $(P<0.05, P<0.01)$. (B) Image of tumors at the end of time point from vehicle, MEL alone, and MEL combined with miR-183 mimics groups. (C) Tumor weight at 4 weeks $(P<0.01)$. (D) Mouse body weight changes during treatment for each group. $* P<0.05$, $* * P<0.0$ I compared with control group.

Abbreviations: DMSO, dimethyl sulfoxide; MEL, melittin.

cellular flow cytometry and in vivo tumor TUNEL assay demonstrated that melittin treatment resulted in a significant increase in the apoptotic cell population compared with the vehicle group.

miR-183 has been observed in a wide variety of malignant tumors including hepatocarcinoma, gastric carcinoma, colon cancer, lung cancer, breast cancer, and pancreatic cancer. ${ }^{11-18}$ Additionally, several recent studies have reported that miR-183 exhibits tumor-activating features in lung cancer and gastric carcinoma. ${ }^{11,15,18} \mathrm{With}$ this in mind, the potential role of miR-183 in melittin-induced NSCLC NCI-H441 cell apoptosis was investigated in the present study. The present study revealed that melittin treatment resulted in a robust increase of apoptosis in NCI-H441 cells and tumors, and this was associated with a significant repression of miR-183 expression. Therefore, the inhibitory ability of melittin on NSCLC was mediated by the inhibition of miR-183. To validate this hypothesis, miR-183 mimics were used to block the function of melittin on endogenous miR-183. With miR-183 mimics treatment, the antitumor effect of melittin were significantly decreased, which was comparable to vehicle group.
Then, we further investigated the predicted target of miR-183. Previously, it has been reported that CASP2 was one of the predicted miR-183 downstream gene candidates. ${ }^{16} \mathrm{We}$ found and validated CASP2 as the direct target of miR-183 using bioinformatics and functional reverse assays.

Given the results of knockdown or overexpression of CASP2 in knockout mice or in cells, CASP2 has been recognized to play an essential role in cell apoptosis and tumorigenesis as a tumor suppressor. ${ }^{27,28}$ There are several lines of evidence that implicate an essential role for CASP2 in human cancers. ${ }^{27-34}$ These include the identification of CASP2 mutations in colorectal and gastric cancers, and in addition, the finding that reduced CASP2 expression correlates with poor prognosis, outcome, and chemotherapeutic drug resistance in acute myeloid leukemia and acute lymphocytic leukemia. ${ }^{31,32}$ Furthermore, miRNAmediated epigenetic silencing was thought to underlie CASP2-reduced expression along with loss of function in human tumors. ${ }^{33}$ Here, the investigations of CASP2 have demonstrated its functional significance in the progression of NSCLC. Interestingly, we found that CASP2 could 
A
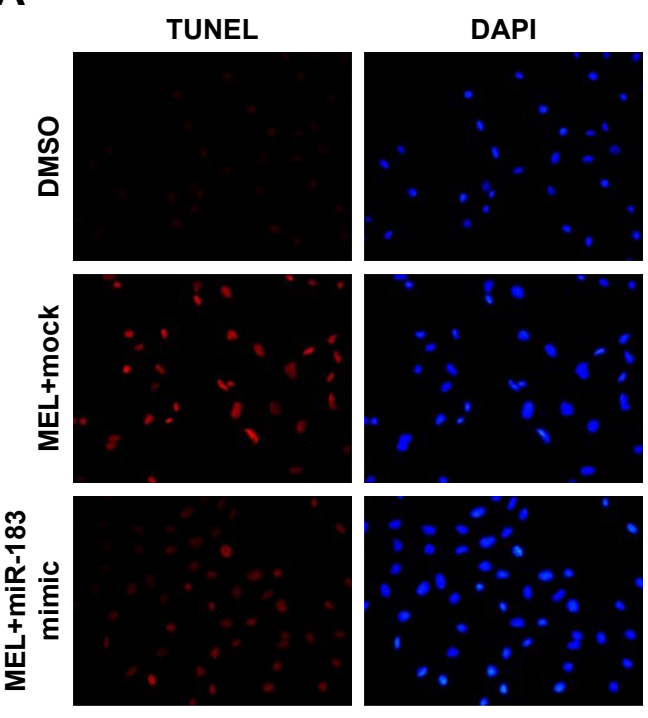

C

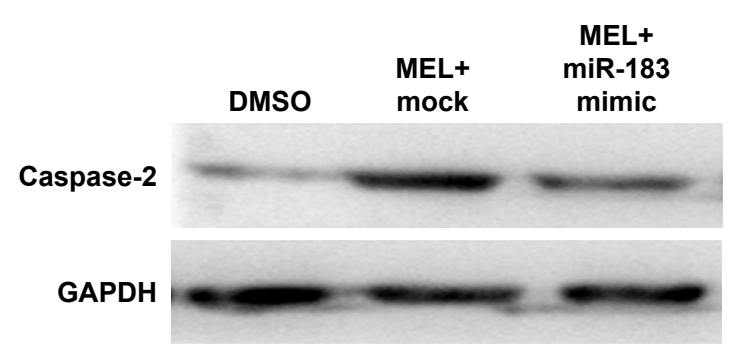

B
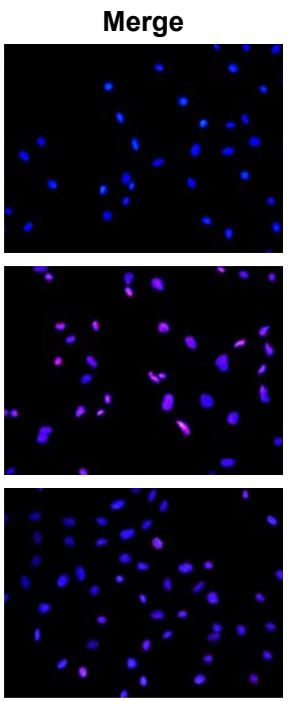

D

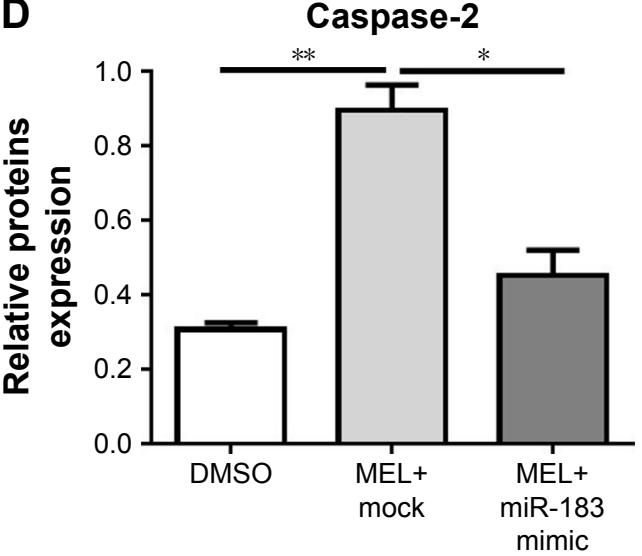

Figure 6 MEL induces $\mathrm{NCl}-\mathrm{H} 44 \mathrm{I}$ xenograft apoptosis in vivo.

Notes: (A) The apoptosis of tumor tissue from NCl-H44I xenograft model was detected with TUNEL assay. (B) Calculation of TUNEL-positive cells (per field at 200X magnification; $P<0.0$ I). (C) Caspase-2 protein level was determined by Western blotting. (D) Quantification of caspase-2 protein expression level by normalizing to GAPDH $(P<0.0$ I $) * P<0.05, * * P<0.0$ I compared with control group.

Abbreviations: DAPI, 4',6-Diamidino-2-phenylindole; DMSO, dimethyl sulfoxide; MEL, melittin.

be decreased by melittin, along with the upregulation of Bax, the apoptosis-inducing factor, and downregulation of Bcl-2, the inhibitor of apoptosis. ${ }^{34}$ Moreover, these protein level changes were correlated with the phenotype of cells and tumors which undergo apoptosis with miR-183 treatment. Furthermore, miR-183 mimic rescued the cells from the upregulation of CASP2 induced by melittin, which further demonstrated that melittin via miR-183 increased CASP2 expression to inhibit NSCLC NCI-H441 cell proliferation and tumor growth. Taken together, these findings may provide a promising therapeutic agent (melittin) for future treatment of NSCLC with high miR-183 expression.

\section{Disclosure}

The authors report no conflicts of interest in this work.

\section{References}

1. Okuyama A. Lung cancer incidence rates in the world from the Cancer Incidence in Five Continents XI. Jpn J Clin Oncol. 2018;48(3): 300-301.
2. Gentzler RD, Yentz SE, Johnson ML, Rademaker AW, Patel JD. The changing landscape of phase II/III metastatic NSCLC clinical trials and the importance of biomarker selection criteria. Cancer. 2014;120(24): 3853-3858.

3. Baine MJ, Verma V, Schonewolf CA, Lin C, Simone CB. Histology significantly affects recurrence and survival following SBRT for early stage non-small cell lung cancer. Lung Cancer. 2018;118:20-26.

4. Schabath MB. Risk models to select high risk candidates for lung cancer screening. Ann Transl Med. 2018;6(3):65.

5. Zhou R, Chen KK, Zhang J, et al. The decade of exosomal long RNA species: an emerging cancer antagonist. Mol Cancer. 2018;17(1):75.

6. Peng Z, Pan L, Niu Z, et al. Identification of microRNAs as potential biomarkers for lung adenocarcinoma using integrating genomics analysis. Oncotarget. 2017;8(38):64143-64156.

7. Li C, Yin Y, Liu X, Xi X, Xue W, Qu Y. Non-small cell lung cancer associated microRNA expression signature: integrated bioinformatics analysis, validation and clinical significance. Oncotarget. 2017;8(15): 24564-24578

8. Ooki A, Maleki Z, Tsay JJ, et al. A panel of novel detection and prognostic methylated DNA markers in primary non-small cell lung cancer and serum DNA. Clin Cancer Res. 2017;23(22):7141-7152.

9. Li C, Qin F, Hu F, et al. Characterization and selective incorporation of small non-coding RNAs in non-small cell lung cancer extracellular vesicles. Cell Biosci. 2018;8:2.

10. Dambal S, Shah M, Mihelich B, Nonn L. The microRNA-183 cluster: the family that plays together stays together. Nucleic Acids Res. 2015; 43(15):7173-7188. 
11. Tang $\mathrm{X}$, Zheng $\mathrm{D}, \mathrm{Hu} \mathrm{P}$, et al. Glycogen synthase kinase 3 beta inhibits microRNA-183-96-182 cluster via the $\beta$-Catenin/TCF/ LEF-1 pathway in gastric cancer cells. Nucleic Acids Res. 2014;42(5): 2988-2998.

12. Samanta D, Datta PK. Alterations in the Smad pathway in human cancers. Front Biosci. 2012;17:1281-1293.

13. Qiu Y, Luo X, Kan T, et al. TGF- $\beta$ upregulates miR-182 expression to promote gallbladder cancer metastasis by targeting CADM1. Mol Biosyst. 2014;10(3):679-685.

14. Lodrini M, Oehme I, Schroeder C, et al. MYCN and HDAC2 cooperate to repress miR-183 signaling in neuroblastoma. Nucleic Acids Res. 2013;41(12):6018-6033.

15. Zhang L, Quan H, Wang S, Li X, Che X. miR-183 promotes growth of non-small cell lung cancer cells through FoxO1 inhibition. Tumour Biol. 2015;36(10):8121-8126.

16. Zhu Q, Sun W, Okano K, et al. Sponge transgenic mouse model reveals important roles for the microRNA-183 (miR-183)/96/182 cluster in postmitotic photoreceptors of the retina. J Biol Chem. 2011;286(36): 31749-31760.

17. Ma Y, Liang AJ, Fan YP, et al. Dysregulation and functional roles of miR-183-96-182 cluster in cancer cell proliferation, invasion and metastasis. Oncotarget. 2016;7(27):42805-42825.

18. Zhu W, Zhou K, Zha Y, et al. Diagnostic value of serum miR-182, miR-183, miR-210, and miR-126 levels in patients with early-stage non-small cell lung cancer. PLoS One. 2016;11(4):e0153046.

19. Rady I, Siddiqui IA, Rady M, Mukhtar H, Mellitin MH. Melittin, a major peptide component of bee venom, and its conjugates in cancer therapy. Cancer Lett. 2017;402:16-31.

20. Liu CC, Hao DJ, Zhang Q, et al. Application of bee venom and its main constituent melittin for cancer treatment. Cancer Chemother Pharmacol. 2016;78(6):1113-1130.

21. Socarras KM, Theophilus PAS, Torres JP, Gupta K, Sapi E. Antimicrobial activity of bee venom and melittin against Borrelia burgdorferi. Antibiotics. 2017;6(4):E31.
22. Lee $\mathrm{C}$, Bae SS, Joo H, Bae H. Melittin suppresses tumor progression by regulating tumor-associated macrophages in a Lewis lung carcinoma mouse model. Oncotarget. 2017;8(33):54951-54965.

23. Zhang SF, Chen Z. Melittin exerts an antitumor effect on non-small cell lung cancer cells. Mol Med Rep. 2017;16(3):3581-3586.

24. Oršolić N. Bee venom in cancer therapy. Cancer Metastasis Rev. 2012; 31(1-2):173-194.

25. Justus CR, Leffler N, Ruiz-Echevarria M, Yang LV. In vitro cell migration and invasion assay. J Vis Exp. 2014;88:e51046.

26. Livak KJ, Schmittgen TD. Analysis of relative gene expression data using real-time quantitative PCR and the 2(-Delta Delta C(T)) method. Methods. 2001;25(4):402-408.

27. Imre G, Rajalingam K. Apoptosis inhibitor 5: role in the inhibition of caspase-2. Cell Cycle. 2018;17(4):397-398

28. Puccini J, Dorstyn L, Kumar S. Caspase-2 as a tumour suppressor. Cell Death Differ. 2013;20(9):1133-1139.

29. Lee H, Shin EA, Lee JH, et al. Caspase inhibitors: a review of recently patented compounds (2013-2015). Expert Opin Ther Pat. 2018;28(1): 47-59.

30. Miles MA, Kitevska-Ilioski T, Hawkins CJ. Old and novel functions of caspase-2. Int Rev Cell Mol Biol. 2017;332:155-212.

31. Kim MS, Kim HS, Jeong EG, Soung YH, Yoo NJ, Lee SH. Somatic mutations of caspase-2 gene in gastric and colorectal cancers. Pathol Res Pract. 2011;207(10):640-644.

32. Holleman A, den Boer ML, Kazemier KM, et al. Decreased PARP and procaspase-2 protein levels are associated with cellular drug resistance in childhood acute lymphoblastic leukemia. Blood. 2005;106(5):1817-1823.

33. O'Byrne KJ, Richard DJ. Nucleolar caspase-2: protecting us from DNA damage. J Cell Biol. 2017;216(6):1521-1523.

34. Kroemer G. Mitochondrial control of apoptosis: an introduction. Biochem Biophys Res Commun. 2003;304(3):433-435.

35. Xiao F, Zuo Z, Cai G, Kang S, Gao X, Li T. miRecords: an integrated resource for microRNA-target interactions. Nucleic Acids Res. 2009;37:D105-D110. 


\section{Supplementary materials}
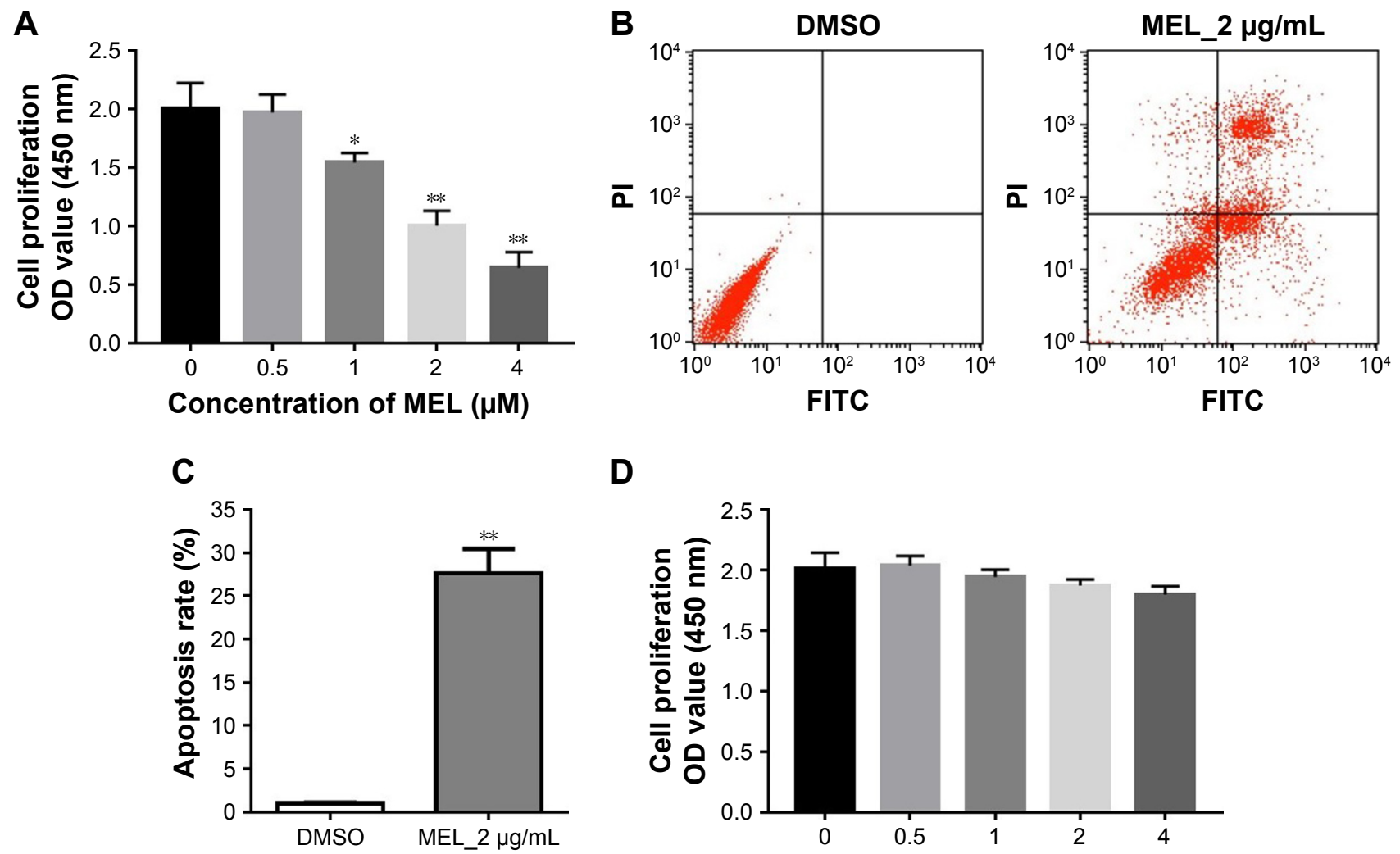

D

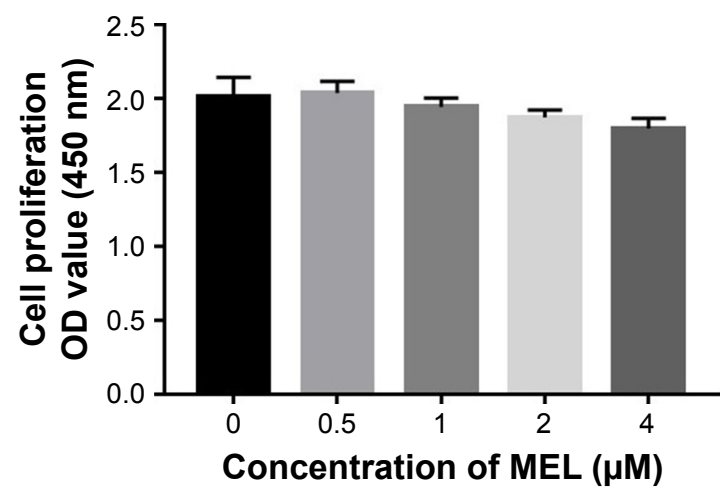

Figure SI Effects of MEL on lung cancer and normal lung epithelial cells.

Notes: (A) A549 cell proliferation rate was detected with MTT assay on treatment with MEL $(0,0.5, I, 2$, or $4 \mu \mathrm{g} / \mathrm{mL})$ for 72 hours $(P<0.05, P<0.01)$. (B, C) Annexin V/PI was used to validate the cell apoptotic rate of A549 cells exposed to $2 \mu \mathrm{g} / \mathrm{mL}$ MEL for 72 hours $(P<0.01)$. (D) BEAS-2B cell proliferation rate was detected with MTT assay on treatment with MEL $(0,0.5, \mathrm{I}, 2$, or $4 \mu \mathrm{g} / \mathrm{mL})$ for 72 hours. $* P<0.05$, $* * P<0.01$ compared with DMSO group.

Abbreviations: DMSO, dimethyl sulfoxide; FITC, fluorescein isothiocyanate; MEL, melittin; PI, propidium iodide. 


\section{A}
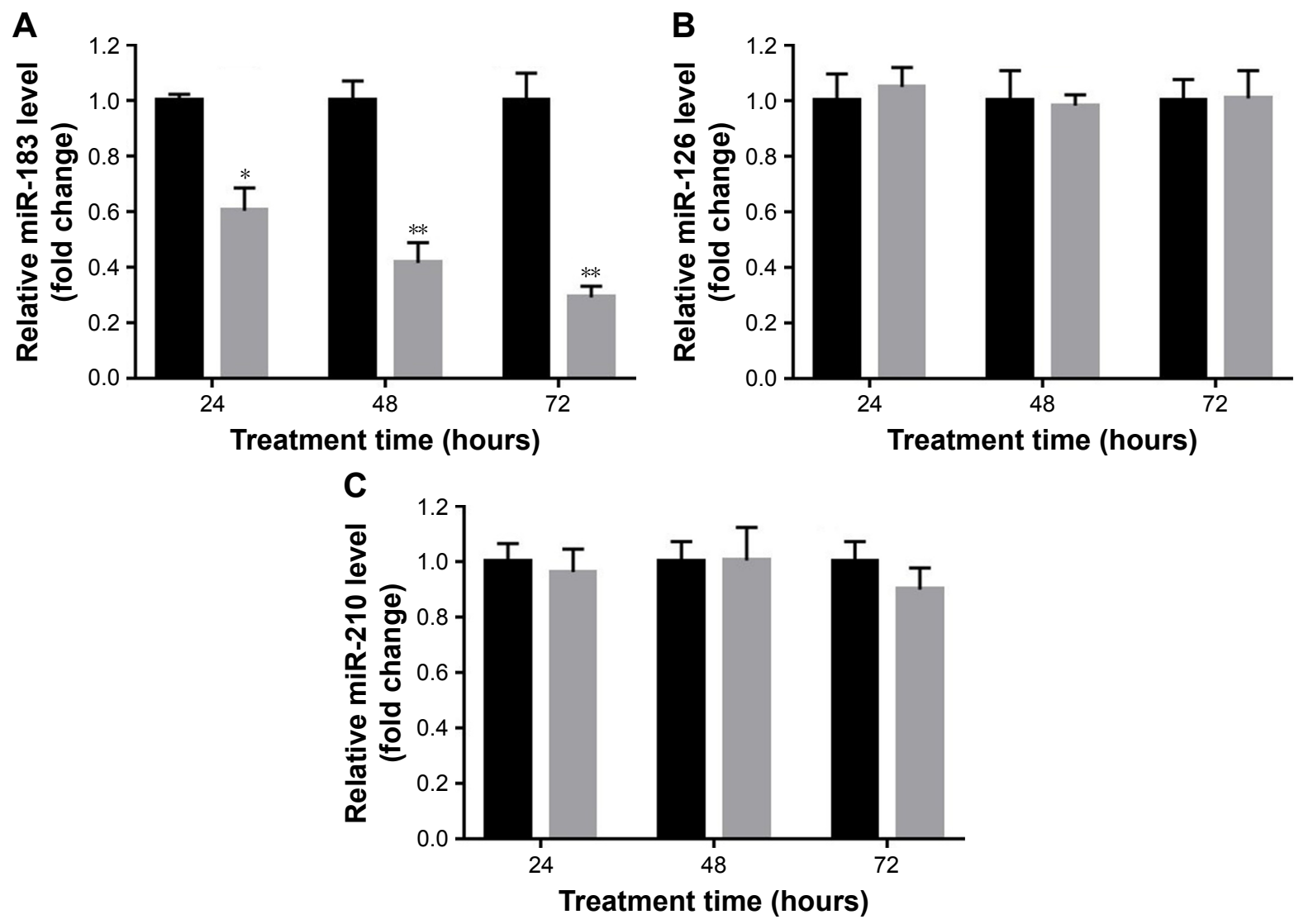

DMSO $\quad$ MEL_2 2 M

Figure S2 MEL downregulates miR- 183 mRNA expression levels.

Note: (A-C) miR-183, miR-126, and miR-210 mRNA expression levels were detected with RT-qPCR in NCl-H44I cells treated with MEL (2 $\mu g / \mathrm{mL})$ for 24,48 , and 72 hours. $* P<0.05$, ** $P<0.01$ compared with DMSO group.

Abbreviations: DMSO, dimethyl sulfoxide; MEL, melittin; RT-qPCR, reverse transcriptase quantitative polymerase chain reaction.

OncoTargets and Therapy

\section{Publish your work in this journal}

OncoTargets and Therapy is an international, peer-reviewed, open access journal focusing on the pathological basis of all cancers, potential targets for therapy and treatment protocols employed to improve the management of cancer patients. The journal also focuses on the impact of management programs and new therapeutic agents and protocols on

\section{Dovepress}

patient perspectives such as quality of life, adherence and satisfaction. The manuscript management system is completely online and includes a very quick and fair peer-review system, which is all easy to use. Visit http://www.dovepress.com/testimonials.php to read real quotes from published authors. 